\title{
Estimating sea turtle exposures to Deepwater Horizon oil
}

\author{
Bryan P. Wallace ${ }^{1,2, *}$, Brian A. Stacy ${ }^{3}$, Matthew Rissing ${ }^{1}$, Dave Cacela ${ }^{1}$, \\ Lance P. Garrison ${ }^{4}$, George D. Graettinger ${ }^{5}$, James V. Holmes ${ }^{1}$, Trent McDonald ${ }^{6}$, \\ Danya McLamb ${ }^{7}$, Barbara Schroeder ${ }^{3}$ \\ ${ }^{1}$ Abt Associates, Inc., Boulder, CO 80302, USA \\ ${ }^{2}$ Nicholas School of the Environment, Duke University Marine Lab, Beaufort, NC 28516, USA \\ ${ }^{3}$ Office of Protected Resources, NOAA Fisheries, Silver Spring, MD 20910, USA \\ ${ }^{4}$ Southeast Fisheries Science Center, NOAA Fisheries, Miami, FL 33149, USA \\ ${ }^{5}$ Office of Response and Restoration, NOAA, Seattle, WA 98115, USA \\ ${ }^{6}$ Western EcoSystems Technology, Inc., Laramie, WY 82070, USA \\ ${ }^{7}$ Industrial Economics, Inc., Cambridge, MA 02140, USA
}

\begin{abstract}
The Deepwater Horizon (DWH) oil spill was unprecedented in extent and duration, and affected marine natural resources, including sea turtles, throughout the northern Gulf of Mexico. Consequently, US federal and state Trustees documented and quantified oil exposure and resulting injuries to sea turtles under the DWH Natural Resource Damage Assessment. At-sea rescue operations focused on surface-pelagic juvenile sea turtles, which were especially at risk to oil exposure within oceanic convergence zones, and provided direct observations of the degree that turtles in this young life stage were exposed to DWH oil. In contrast, locations of larger neritic juvenile and adult turtles were documented during aerial surveys, but because these turtles were not captured, their oiling status could not be directly evaluated. Both the rescue operations and aerial surveys were able to observe only a small fraction of sea turtles within the vast spill footprint. We developed a spatio-temporally explicit approach that used direct observations of oiled surface-pelagic juvenile sea turtles and satellite-derived surface oil distributions to statistically estimate the probabilities of oil exposure for all sea turtles that were present within the area of the DWH spill, but whose oiling status was unknown. Our results enabled an expansion of exposure and injury quantification across the entire DWH spill area and period. This approach was conceptually straightforward and used common geospatial and statistical techniques, making it applicable to other situations in which the full extent of oil exposure for marine natural resources must be estimated from an incomplete sample.
\end{abstract}

KEY WORDS: Deepwater Horizon oil spill · Natural Resource Damage Assessment · Oil exposure · Oil spills $\cdot$ Sea turtles

\section{INTRODUCTION}

Under the Oil Pollution Act of 1990, United States (US) federal and state agencies charged with stewardship of natural resources must quantify 'injury' (i.e. an observable or measurable adverse change in

${ }^{*}$ Corresponding author: bryan_wallace@abtassoc.com a natural resource or impairment of a natural resource service) caused by oil spills as part of a legal process called Natural Resource Damage Assessment (NRDA). Damages quantified under the NRDA process ultimately serve as the basis for restitution required of the party(ies) responsible for the spill.

(C) The authors and (outside the USA) the US Government 2017. Open Access under Creative Commons by Attribution Licence. Use, distribution and reproduction are unrestricted. Authors and original publication must be credited.

Publisher: Inter-Research · www.int-res.com 
Sea turtles - all species of which are federally listed under the US Endangered Species Act-were among the key taxa assessed in the NRDA for the Deepwater Horizon (DWH) oil spill, which contaminated a vast area of the northern Gulf of Mexico (GoM) in 2010 after the massive release of oil and other substances from BP's Macondo well (DWH Trustees 2016a). The spill area overlapped with the distribution of 5 species of sea turtles: Kemp's ridleys Lepidochelys kempii, loggerheads Caretta caretta, green turtles Chelonia mydas, hawksbills Eretmochelys imbricata, and leatherbacks Dermochelys coriacea (Wallace et al. 2010, Shaver et al. 2013, Hart et al. 2014, Lamont et al. 2015).

A key metric of 'injury' under the NRDA framework is the number of animals killed as a result of the spill or related response actions. Sea turtles have multiple life history stages with different (but not completely discrete) distributions within the GoM, all of which were susceptible to exposure to oil from the DWH spill when it occurred in offshore waters, spread into continental shelf areas, and washed onto the coast (DWH Trustees 2016b). Consequently, the NRDA required comprehensive consideration of all life stages to determine the full nature and extent of sea turtle injuries. Specifically, this study focuses on surface-pelagic juvenile turtles, which are principally found in the oceanic zone, and neritic turtles, which are larger juvenile and adult turtles typically found in waters over the continental shelf and closer to shore (Bolten 2003).

Surface-pelagic juvenile sea turtles were especially threatened by the DWH spill because offshore convergence zones bring together anything floating at the surface, including Sargassum, sea turtles and their prey, and, in the case of the DWH spill, oil (Stacy 2012). These convergence zones are vital habitats for sea turtles in this life stage (Bolten 2003, Witherington et al. 2012). Therefore, to mitigate harm to sea turtles that rely on these surface habitats, rescue teams conducted more than 1200 boat-based rescue operations during the spill that primarily focused on offshore convergences between late May and early September 2010. These rescue operations documented the extent of oil exposure on individual animals, confirmed death of sea turtles resulting from physical miring (Stacy 2012), and enabled the estimation of densities and abundance of surfacepelagic juveniles within the expansive area of the spill (McDonald et al. 2017, this Theme Section). However, these were partial samples of the actual number of turtles that were present and potentially exposed to oil; the sheer size and duration of the spill and logistical constraints (e.g. limited resources, restrictions on operations near the wellhead, inclement weather) limited rescue operations to a small fraction of the total spill footprint and period (DWH Trustees 2016b). Therefore, additional approaches were needed to quantify and characterize exposure of all turtles within the spill area in order to more comprehensively inform the NRDA.

Many neritic turtles were also present within the spill area (Garrison 2015). However, because these animals are more widely dispersed and spend less time at the sea surface than pelagic juveniles (Bolten 2003), they could not be as efficiently sighted and captured by boat-based operations. Therefore, documentation of the spatio-temporal distribution of neritic sea turtles throughout the DWH spill area and period required synoptic aerial surveys on the continental shelf throughout the northern GoM (i.e. to the 200-m isobath) (Garrison 2015). Overall, the aerial surveys covered more than 18000 linear kilometers along nearly 250 transects between April and September 2010 (Garrison 2015). The turtle sightings data obtained during these surveys were used to estimate neritic sea turtle densities and abundance over time (Garrison 2015). However, because turtles were not captured, their oiling status could not be directly examined. Similar to the unobserved surface-pelagic juvenile turtles, this lack of direct observational data presented an obstacle to comprehensive quantification of sea turtle exposures and injury during the DWH spill.

Because all sea turtles must spend time at the surface to breathe, rest, bask, and feed, these fundamental behaviors put turtles at continuous and repeated risk of exposure anywhere that the ocean surface was contaminated with DWH oil (DWH Trustees 2016b). Based on veterinary assessments of oiled juvenile turtles collected during the DWH spill, physical fouling in heavy surface oil was the most readily apparent, immediately harmful result of oil exposure (Stacy 2012). Turtles that were heavily fouled were considered unlikely to survive without human intervention (Stacy 2012); thus, the DWH sea turtle injury assessment prioritized estimation of the total numbers of heavily oiled turtles. In addition, the assessment also estimated the numbers of turtles that were exposed to oil to less severe degrees (Stacy 2012, McDonald et al. 2017); studies of the toxic effects of oil exposure on other vertebrate taxa indicated that less extensive exposure could also lead to chronic or sublethal effects (Mitchelmore et al. 2017, this Theme Section).

Similar concerns about exposure to surface oil were warranted for neritic turtles as well. Limited ob- 
servations of impaired, oiled larger turtles during the DWH spill (B. Witherington, Disney's Animal Kingdom, Lake Buena Vista, FL, pers. comm.) and previous reports of oiling associated with death or stranding (Shigenaka 2003, Camacho et al. 2013) indicated that larger turtles were also vulnerable to the effects of oil. Therefore, any turtle in the DWH spill footprint was at risk of exposure to surface oil, and the degree of oiling was regarded as a critical measurable parameter relevant to mortality. This did not preclude adverse effects from more cryptic or complex routes of exposure, such as inhalation or chemical exposure through the food web, but offered the most straightforward, evidence-based approach. Taken together, these conclusions provided a biological context for the rationale to use observed turtle oiling status to estimate the oiling status of turtles that were not directly assessed but that experienced similar environmental conditions, specifically the proximity and persistence of surface oil.

The goal of this study was to estimate the extent to which all turtles were potentially exposed to DWH oil, thereby enabling expansion of exposure and injury quantification beyond the small fraction of directly assessed turtles to all turtles that were present within the footprint area of DWH oil (DWH Trustees 2016b). To accomplish this goal, our first objective was to describe statistical relationships between the observed degrees of oiling of rescued juvenile turtles and potentially associated factors, specifically the proximity and persistence of surface oil. The second objective was to use these relationships to estimate the degree of oiling for all turtles that were sighted or projected to have been within the spill area but were not captured and evaluated for oiling status. Our results facilitated a more complete quantification of exposures and injuries to sea turtles in the northern GoM caused by the DWH oil spill (DWH Trustees 2016b).

\section{METHODS}

In the sections that follow, we describe in detail the sequential phases of the modeling approach used to estimate degree of oil exposure for sea turtles during the DWH oil spill; results of initial analyses that helped us refine and finalize this approach are also described below to illustrate the iterative process. The modeling approach that we developed was used to quantify total exposures to oil and mortality of surface-pelagic turtles and neritic turtles (DWH Trustees 2016b, Garrison 2015, McDonald et al. 2017). Density and abundance, as well as exposures and injuries, were quantified separately for these 2 general life stages based on differences in assessment methods and available data as described above and by the DWH Trustees (2016b), Garrison (2015), and McDonald et al. (2017). Accordingly, adaptations to our modeling approach were required to estimate the degree of oil exposure separately for these 2 groups. For neritic phase animals, the systematic aerial surveys provided comprehensive abundance estimates (Garrison 2015), but did not characterize exposure; thus, our model was intended to classify the level of exposure based on spatial and temporal distribution of these larger turtles relative to factors potentially associated with oil exposure. For surfacepelagic juveniles, the rescue operations yielded direct observations of oiling that allowed assignment of turtles to different degrees of oiling (Stacy 2012), and analysis of search transect data provided density estimates for sea turtles by degree of oiling (McDonald et al. 2017). Thus, we adapted our modeling approach for this life stage to define the areal extent of potential oil exposure to which these densities could be applied (i.e. the area within which turtles were most susceptible to exposure to surface oil). Here we briefly introduce our step-wise methodological approach, which is described below in more detail.

In Phase 1, we explored spatial (e.g. distance from the wellhead where a turtle was captured) and temporal (e.g. date of turtle capture) factors associated with sea turtle oil exposure to identify candidate variables for statistical classification of degree of turtle oiling.

In Phase 2, we examined the relationship between degree of oiling and satellite-detected surface oil observed in the area and time before turtles were captured and evaluated. This step included quantification of intersections between surface oil and sea turtles (including their capture dates and locations, and observed degrees of oiling) to estimate oil exposure.

In Phase 3, we developed statistical classification models to describe the relationship between candidate explanatory variables identified in the first 2 phases and degree of turtle oiling. We iteratively tested different combinations of explanatory variables to identify the most robust variables for classifying degree of turtle oiling. These models were applied to estimate oiling probabilities for neritic turtles that were sighted within the DWH oil footprint but not directly evaluated for degree of oil exposure. These oiling probabilities were then used to estimate total exposures of neritic turtles present within the DWH footprint during the spill (Garrison 2015, DWH Trustees 2016b). 
Finally, in Phase 4, we adapted this probability estimate approach to the full spatial and temporal extent of the DWH spill footprint to create a generalized description of degree of oil exposure at the sea surface across the cumulative oil footprint. The purpose of this step was to provide areal extents to which turtle density estimates (McDonald et al. 2017) could be applied to enable calculation of surfacepelagic turtle abundance, exposures, and mortality (DWH Trustees 2016b).

\section{Phase 1: Exploring spatial and temporal factors associated with sea turtle oil exposure}

We reviewed information about the date and location of turtle captures relative to observed degrees of oiling (i.e. the extent to which turtles' bodies were externally oiled) to identify potential candidate variables for statistical classification of oiling categories (unoiled, minimally, lightly, moderately, and heavily oiled; Stacy 2012). Following initial review of the spatio-temporal distribution of turtles based on the observed degree of oiling, distance between turtle capture locations and the wellhead (i.e. sea surface coordinates of the wellhead location), turtle capture dates, and observed oil in the vicinity of where turtles had been captured on the days immediately prior to capture were included in subsequent analyses, as described below.

Determination of surface oil presence. Synthetic aperture radar (SAR) has long been used to detect oil on water (e.g. Garcia-Pineda et al. 2009), and was widely used to delineate the presence of oil on the ocean surface on a daily basis during the DWH spill (Leifer et al. 2012, ERMA 2015, Graettinger et al. 2015). Numerous SAR satellites collected data over the northern GoM during the summer of 2010; the Trustees' analyses included images from at least 8 different satellites (Graettinger et al. 2015).

For the present study, 171 SAR images were analyzed for oil, covering 89 days between April 23 and August 11, 2010; DWH oil was detectable on the ocean surface starting shortly after the explosion of the drill rig, and continuing until about 1 mo after the leaking wellhead was capped (Graettinger et al. 2015, DWH Trustees 2016c). On some days, multiple SAR images covering the entire northern GoM were available; on other days, there were no available SAR images (Graettinger et al. 2015). When multiple images overlapped in a single day, a composite daily image was created using all the detectable oil in the daily SAR images overlaid in a geographic informa- tion system (GIS). The output was a composite area of detectable surface oil per day as a single raster image with a 50-m pixel resolution. Each of the 50-m pixels in the GoM had a daily binary observation of oil coverage, which enabled calculation of the cumulative number of days that oil covered the pixel between April 23 and August 11, 2010. This calculation of cumulative oil-days based on SAR data estimated the total amount of time that a particular area was covered with oil.

For those dates and areas where no data were available on a given day ( $\mathrm{n}=22$ of $111 \mathrm{~d}$ ), we assumed that there was no oil, rather than attempting to model the size, shape, and coverage of an unknown daily oil footprint. This simplifying assumption resulted in occasional underestimates of oil coverage. However, data gaps occurred only sporadically during the spill period; generally there was only a single missing day, and never more than 2 consecutive days without data. Furthermore, 9 of the days with no coverage occurred after the well was capped (July 15, 2010) and surface oil began to dissipate. Therefore, we concluded that the existing SAR data with no interpolation were sufficient for characterizing the presence of surface oil across the DWH footprint throughout the spill period during which turtles were observed.

Turtle capture data and factors potentially related to oil exposure. All heavily oiled surface-pelagic turtles were found before August 1, 2010 (Fig. 1A), and more than $90 \%$ of heavily oiled turtles were found within $90 \mathrm{~km}$ (straight-line distance) of the wellhead (Fig. 1B). The degree of oiling of turtles observed in the field increased with cumulative oil-days at the location of turtle capture and decreased with increasing distance of turtles from the wellhead (Fig. 1B).

Given that an objective of this study was to use direct observations of oil exposure to surface-pelagic turtles to estimate oil exposure for neritic turtles, we performed preliminary comparisons of the 2 datasets (i.e. boat-based rescues of surface-pelagic turtles and aerial surveys of neritic turtles) to characterize how similarities and differences might influence our analytical approach. Specifically, we plotted the distributions of distances from the wellhead and cumulative oil-days for turtle captures and sightings during rescue operations and aerial survey sighting locations (Fig. 2). Due to differences in relative spatial extent of these 2 survey methods, more turtle captures and sightings during rescue operations occurred in close proximity to the wellhead area (Fig. 2A) and in locations with high cumulative oiling (Fig. 2C) than did turtle sightings during aerial surveys (Fig. 2B,D) 

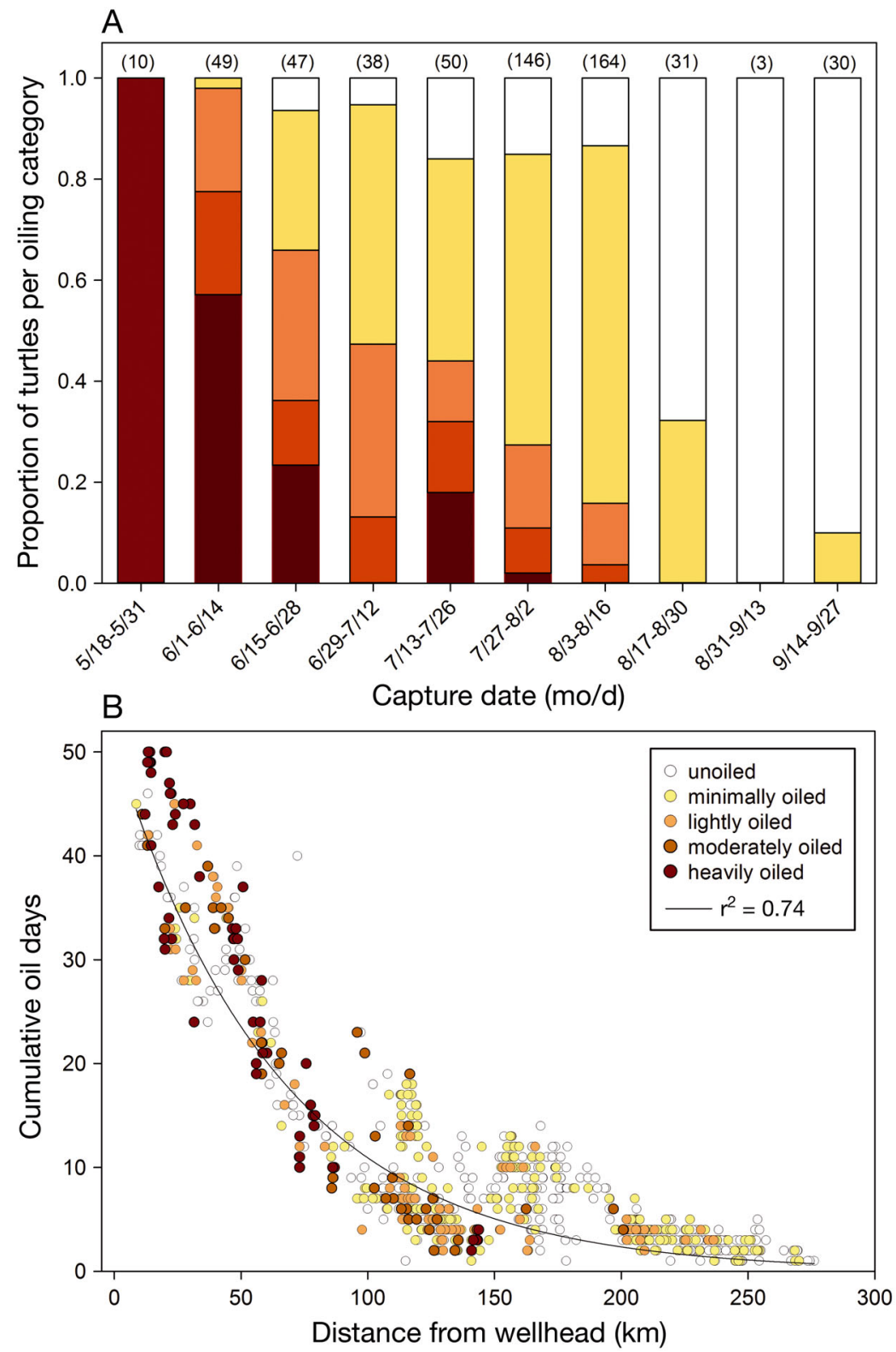

Fig. 1. Observed degree of oiling on sea turtles rescued during Deepwater Horizon disaster response operations (A) by capture date (in 2010) binned into 2-wk intervals: numbers of turtles given in parentheses; and (B) by distance from wellhead and cumulative oil-days (i.e. cumulative number of days that satellite imaging detected surface oil) at capture locations: cumulative oil days $=50.8^{\left(-0.0154^{*} \text { distance }\right)}\left(\mathrm{r}^{2}=0.74, \mathrm{p}<0.0001\right)$. Color key for the degree of oiling applies to both panels. Turtle capture efforts were not conducted uniformly in time or space during the spill; they did not begin until late May, and were lower on July 1-6 due to bad weather; high-intensity rescue operations concluded in mid-August, being wound down to spot-checks

2012, McDonald et al. 2017). In contrast, distances from the wellhead of turtles sighted during aerial surveys resemble a normal distribution (Fig. 2B). Aerial surveys were conducted over a relatively continuous area on the continental shelf (i.e. out to the 200-m isobath), an area that was slightly westward compared to rescue operations (Garrison 2015).

Phase 2: Estimating oil exposure by quantifying intersections between turtles and surface oil

Field data demonstrated that heavily oiled turtles (1) suffered severe, adverse effects of oil exposure, including death (Stacy 2012); (2) were observed primarily during the period of free release of oil, before or shortly after the wellhead was capped on July 15, 2010 (Fig. 1A); (3) were observed relatively close to the wellhead (Fig. 1B); and (4) were captured in areas that had more detectable surface oil during the spill (Fig. 1B). Given the primacy of exposure to surface oil in describing potential mortality of sea turtles, we developed an approach to analyze turtle captures and sightings in the context of integrated spatio-temporal information about surface oil. Specifically, our goal was to answer the question, 'What did it take for a turtle to get oiled to a certain degree?'

Characterizing the surface oil environment using satellite-derived oil data. To answer this question, we used daily oil coverage from analyses of SAR data to quantify the spatial and temporal proximity of turtles to surface oil and to describe the oil environment before turtles were captured and evaluated. Specifically, we intersected the location of each captured turtle with the

(Garrison 2015, McDonald et al. 2017, DWH Trustees 2016b). The non-uniform distribution of rescue efforts in space and time is evident in a trimodal distribution of distances from the wellhead of captured and sighted turtles (Fig. 2A); this pattern reflects the 3 ports from which operations were based (Stacy location of surface oil during the days before capture, varying both the size of the buffer area around the capture location and the number of prior days of oil coverage (see below). We then related the number of daily oil footprint intersections to the observed degree of oiling (Fig. 3). 


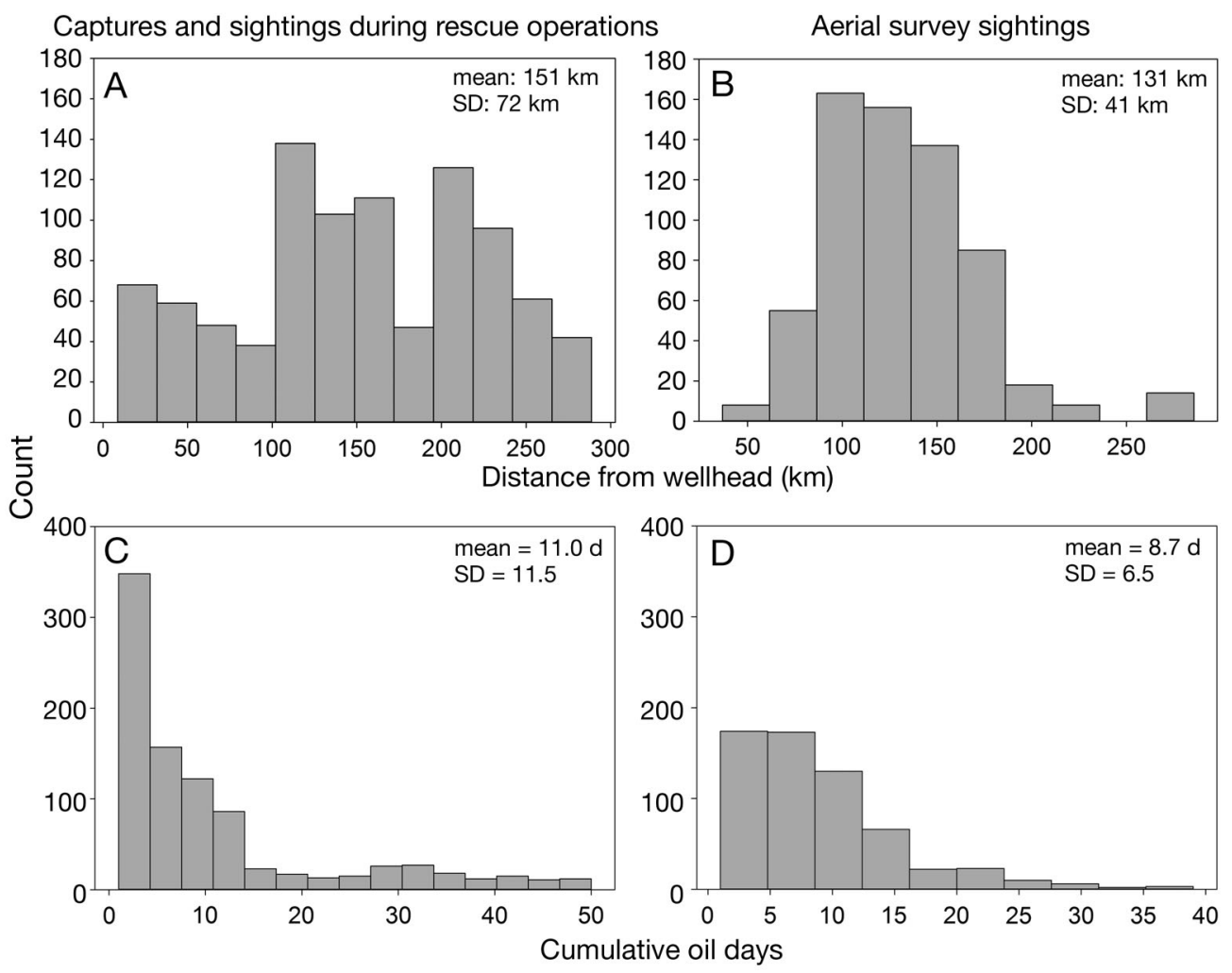

Fig. 2. $(\mathrm{A}, \mathrm{B})$ Distance from the wellhead and $(\mathrm{C}, \mathrm{D})$ cumulative oildays where sea turtles were documented during $(\mathrm{A}, \mathrm{C})$ rescue operations (i.e. surface-pelagic turtles) and $(\mathrm{B}, \mathrm{D})$ aerial surveys (i.e. neritic turtles)

First, we developed several scenarios to quantify spatio-temporal overlap between turtle locations and daily oil footprints. To account for the area that surface-pelagic turtles occupied during the period before researchers found them, either while turtles were actively swimming or while they were passively drifting in surface currents (Putman \& Mansfield
2015), we modeled circular distance buffers around each turtle location (Fig. 3, Step 1). These spatial buffers also indirectly accounted for the movement of oil through the surface environment over time, which was necessary because SAR imagery was generally not collected synoptically with turtle observation data. In addition to these spatial buffers, we included
Step 1:

Turtle location buffered to account for movements

Step 2:

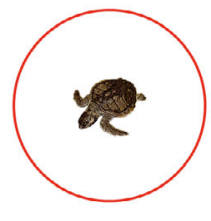

Count intersections with surface oil during period prior to capture/sighting date

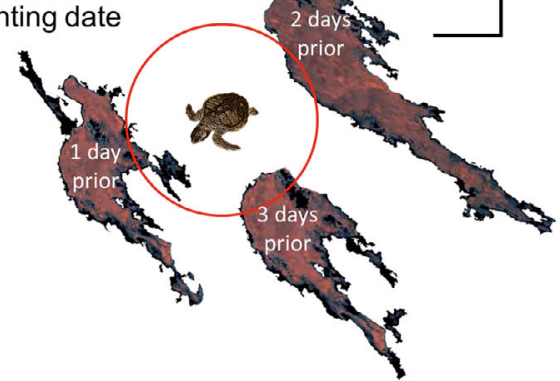

Step 3:

Relate number of oil intersections

to observed degree of oiling from rescued turtles to estimated probability of heavy oiling

Step 4:

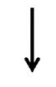

Use numbers of intersections in statistical models that estimate degree of oiling of turtles with known oiling status

Step 5:

Use best-performing model to estimate degree of oiling observed but not assessed for oiling status
Fig. 3. Schematic of the modeling approach used to quantify the number of days of surface oil intersections for spatio-temporally buffered turtle locations; for a detailed description of each step, see 'Methods: Phase 2'. Resulting values were used to develop statistical models to estimate the degree of turtle oiling 
a temporal component by varying the number of days that a spatially buffered turtle location might have intersected daily oil footprints before the turtle's capture date (Fig. 3, Step 2).

These paired spatial and temporal variables were not strictly defined by the movement rates of surfacepelagic juvenile sea turtles. Turtles in this life stage often remain passively entrained in surface convergence area habitats that aggregate Sargassum and other floating materials (Bolten 2003, Witherington et al. 2012). However, these small juvenile sea turtles are also capable of active swimming over long distances and time periods to remain in certain areas (Putman \& Mansfield 2015). Regardless of whether their travel is passive or active, the direction, magnitude, and speed of turtles' movements can vary tremendously (Mansfield et al. 2014, Putman \& Mansfield 2015). Predicting the directionality, magnitude, and shape of the area that they could have covered in the time before being rescued by response crews was therefore beyond the scope of our assessment. In addition, because we needed to use the same approach for larger neritic turtles, we chose values for the spatio-temporal scenarios that would be applicable to both life stages. Hence, we constructed scenarios that (1) would conservatively estimate the area within which oceanic and neritic turtles might have been located in a given time period, and (2) would be meaningful within the spatiotemporal scale of the DWH oil spill and oil footprint.

The spatio-temporal scales and general approach to quantifying daily oil footprint intersections are biologically reasonable for multiple reasons. First, the total area that we included within the broadest-scale circular spatial buffer (10.5-km radius; Table 1 ) around turtle capture locations was approximately $350 \mathrm{~km}^{2}$, which was between the estimates of high-use areas (reported as 50\% kernel density estimates) for adult female loggerheads $\left(100.7 \pm 141.8 \mathrm{~km}^{2}\right.$; Hart et al. $2014)$ and Kemp's ridley turtles $\left(660.8 \pm 899.4 \mathrm{~km}^{2}\right.$; Shaver et al. 2013). Second, surface-pelagic turtles in the northern GoM tend to orient their movements to remain near the continental shelf in the northern GoM rather than drift passively into the open ocean in the central GoM (Putman \& Mansfield 2015). This observation is relevant because we assumed that, before their capture, turtles remained within $10.5 \mathrm{~km}$ of their capture location, and therefore would have been exposed to oil present in the northern GoM during that period.

Next, we constructed multiple spatio-temporal scenarios to characterize patterns in the accumulation of daily oil intersections. We performed a cross-factorial
Table 1. Spatial buffers (radius) around turtle locations and temporal windows before turtle capture dates used to quantify satellite imaging intersection quantification. Model scenarios used cross-factorial combinations of these values to evaluate model performance

\begin{tabular}{|lcc|}
\hline Scale & Spatial buffer $(\mathrm{km})$ & Days before capture \\
\hline Finest & 0.5 & 1 \\
& 3.5 & 7 \\
Broadest & 7 & 14 \\
& 10.5 & 21 \\
\hline
\end{tabular}

analysis of distance (for buffering and overlaying features) and time (i.e. the number of days in the intersection window before capture) relative to turtle locations and capture dates, and we used these to build multiple scenarios of intersection parameters based on each time/distance combination. Thus, scenarios were combinations of a spatial buffer around a turtle's location and a temporal window before the date of capture. The scenarios varied from fine-scale (e.g. 0.5-km buffer, $1 \mathrm{~d}$ before capture, where the maximum number of daily oil intersections was 1) to broad-scale (e.g. 10.5-km buffer, $21 \mathrm{~d}$ before capture, where the maximum number of daily oil intersections was 21), and included all possible combinations of spatial and temporal variables within these ranges. Spatial buffers increased 3 to $3.5 \mathrm{~km}$ per week of increased time before turtle capture dates (Table 1), including intermediate, cross-factorial scenarios (e.g. $3.5-\mathrm{km}$ buffer paired with all temporal windows before capture date). Although we examined every possible spatial-temporal combination, we present only the results of the 4 specific scenarios shown in Table 1.

Quantifying intersections between turtles and SAR-detected surface oil. Following the method described above, we quantified the number of intersections between daily SAR-detected surface oil footprints and each turtle that had been captured and evaluated to determine the degree of oiling (Fig. 3, Step 3; see Table 1 for our range of spatio-temporal scenarios). We evaluated multiple scenarios because we had no a priori knowledge of the underlying spatial and temporal relationships between observed oil footprints and the degree of oiling of sea turtles.

In general, the number of intersections increased with an increasing spatial buffer, but the number of intersections increased even more with an increasing period before capture (Fig. 4). This is an intuitive result: increasing the spatial buffer increased the likelihood that a particular intersection would occur and be counted, and increasing the temporal window 


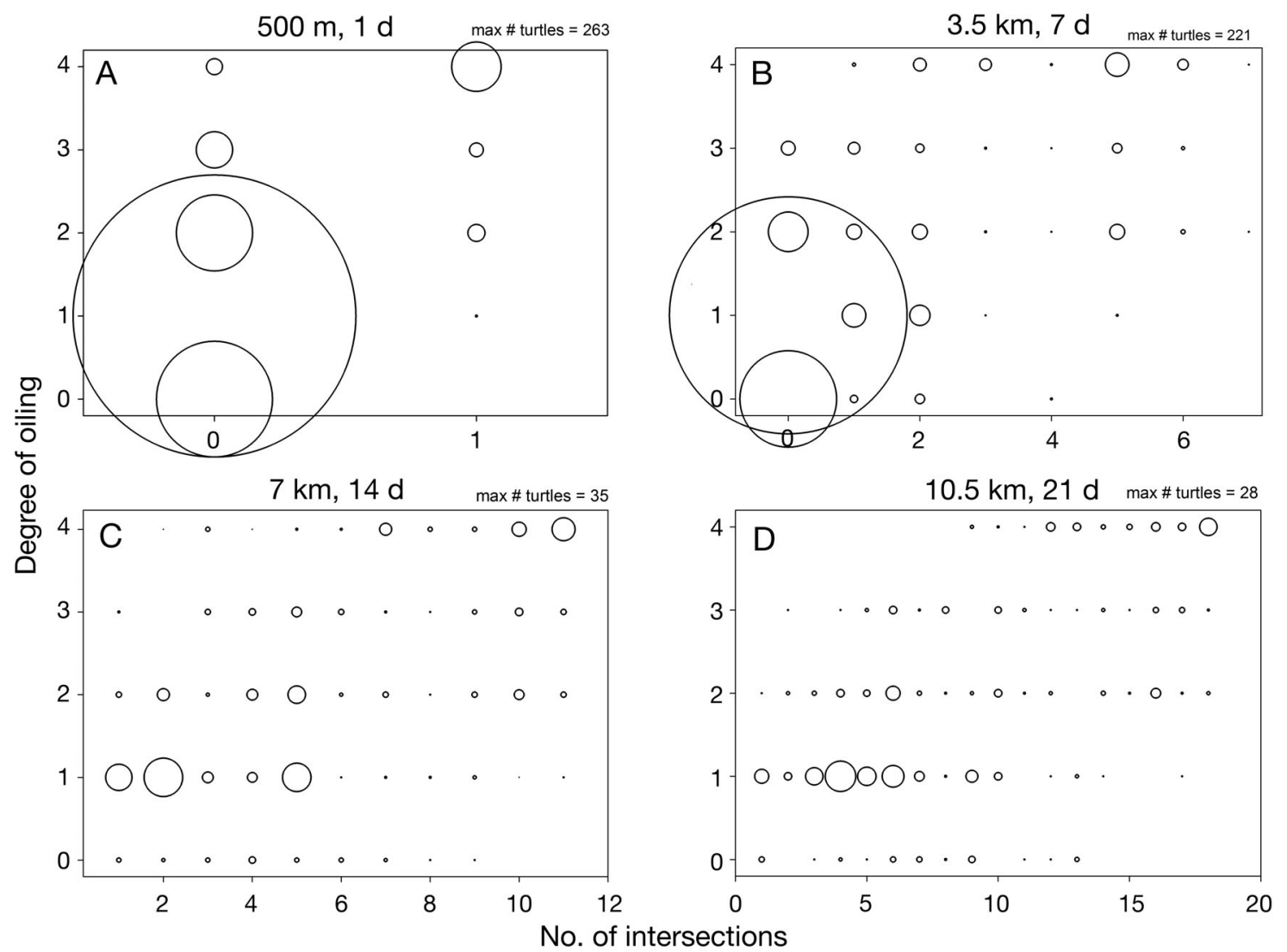

Fig. 4. Observed degree of oiling (class $0=$ unoiled, $1=$ minimally oiled, $2=$ lightly oiled, $3=$ moderately oiled, $4=$ heavily oiled) of turtles rescued during the Deepwater Horizon oil spill generally increased with the number of intersections with daily surface oil footprints between capture locations and dates, across spatio-temporal scales. (A) 0.5-km radius buffer around turtle locations, $1 \mathrm{~d}$ before capture (finest scale); (B) $3.5 \mathrm{~km}, 7 \mathrm{~d}$; (C) $7 \mathrm{~km}, 14 \mathrm{~d}$; (D) $10.5 \mathrm{~km}, 21 \mathrm{~d}$ (broadest scale). Size of circles corresponds to the relative number of turtles for a given combination of number of daily oil footprint intersections and oiling category; circle sizes in all panels are on the same scale

increased the total number of possible daily oil footprints that a turtle could have intersected. Moreover, the spatio-temporal scenarios were nested (i.e. as scenarios increased in spatial and temporal scales, each succeeding scenario included the spatial and temporal scales of the preceding, finer-scale scenario). Thus, the broadest-scale scenario $(10.5-\mathrm{km}$ buffer, $21 \mathrm{~d}$ before capture) contained all daily oil footprint intersections tallied in finer-scale scenarios for the same turtle location and capture date.

Across all spatio-temporal scenarios, the degree of oiling increased with the number of intersections, such that heavily oiled turtles had more intersections with daily oil footprints than turtles in other oiling categories (Fig. 4). At the finest-scale scenario, which could be considered an indication of the probability of acute oil exposure immediately before capture, not a single unoiled turtle had an intersection with the daily surface oil footprint, while more than $60 \%$ of oiled turtles that intersected with the daily surface oil footprint at this scale were heavily oiled (Fig. 4A).
The vast majority of rescued turtles did not have an intersection with the daily surface oil footprint (Fig. 4A), which might reflect the lag time between SAR imagery availability and turtle collection on the 1-d scale. In contrast, all heavily oiled turtles had at least one daily oil footprint intersection in the $3.5-\mathrm{km}$, 7-d scenario (Fig. 4B); at least 3 daily oil footprint intersections in the $7-\mathrm{km}, 14-\mathrm{d}$ scenario (Fig. 4C); and at least 9 daily oil footprint intersections in the 10.5-km, 21-d scenario (Fig. 4D).

\section{Phase 3: Estimating turtle oiling categories using statistical classification models}

Next, we investigated statistical approaches to classify turtles by degree of oil exposure based on variables identified in the previous 2 phases (Fig. 3, Step 4). Our general hypothesis was that turtles found at locations with recent histories of closer and more persistent surface oil (i.e. higher numbers of 
daily oil footprint intersections) would be more likely to experience greater degrees of oiling. To test this general hypothesis and develop a model to classify the oiling status of turtles, we first systematically examined several variables in multinomial models (ordinal logistic regression and classification and regression trees [CART]) that incorporated different combinations of potential explanatory variables to explain observed oiling categories. Second, we evaluated model performance by comparing misclassification rates of estimated oiling categories relative to the actual observed oiling categories of the same turtles. Third, by comparing performance and behavior among models, we identified the most important explanatory variable and simplified our classification scheme from multinomial (i.e. original 5 oiling classes described by Stacy 2012) to binomial (i.e. heavily oiled or not heavily oiled). Fourth and finally, we used this binomial logistic regression approach to estimate the probability that turtles sighted but not evaluated for oiling status were heavily oiled based on the number of daily oil footprint intersections in spatially and temporally proximate environments (Fig. 3, Step 5).

Ordinal logistic regression and CART models. Our statistical investigation involved methodically examining the relationships between various combinations of candidate variables and the degree of turtle oiling. During this investigation, we tried to identify one or more models that performed well as a predictive tool, while remaining parsimonious. In general, both ordinal logistic regression and nonparametric CART approaches use explanatory variables to classify individual data points into classes or categories; for more detailed information about these modeling approaches, see Lemon et al. (2003).

First, we constructed multiple models that incorporated different combinations of candidate variables, including distance from the wellhead, elapsed days (i.e. number of days between the beginning of the spill and the capture date), cumulative oil-days at turtle capture locations, and 1 to 2 different daily oil footprint intersection scenarios. These sets of candidate variables were then used in both ordinal logistic regression and CART models to generate estimates of the degree of turtle oiling for further evaluation.

Next, to compare relative performance among candidate models, we quantified misclassification rates (i.e. the percent of turtles whose estimated oiling categories either underestimated or overestimated their actual oiling categories) within and among observed oiling categories to which rescued turtles had been originally assigned, and between logistic regression and CART results (Fig. 5). When considering all oiling classes, the overall misclassification rates for the majority of models were consistently in the range of 30 to $40 \%$, and misclassifications were evenly divided between overestimates (i.e. model predicted an oiling class higher than actual) and underestimates (i.e. model predicted an oiling class lower than actual).

Upon closer examination of misclassification rates within individual oiling categories, we found that the various regression and CART models provided reliable classifications of extreme oiling categories heavily oiled (class 4), minimally oiled (class 1), and unoiled (class 0) - but provided less reliable classification for the intermediate oiling classes, i.e. lightly oiled (class 2) and moderately oiled (class 3) (Fig. 5). These statistical results reflected the difficulty in objectively classifying turtles into the lightly and moderately oiled categories based on field observations and notes (Stacy 2012). As mentioned previously, the heavily oiled category was the oiling category that was most clearly associated with turtle mortality (DWH Trustees 2016b). For these reasons, the multinomial, 5-category classification scheme was restructured to a binomial classification scheme that focused on distinguishing the heavy oiling category from all other classes. In essence, this approach estimated the probability of turtles being heavily oiled.

To orient this binomial classification approach, we inspected the results of the CART models that used several splitting variables and classified the turtle oiling categories to determine whether any variables were selected more frequently or were better at classifying turtles into oiling categories than others. CART models consistently selected the broad-scale daily oil footprint intersection scenario $(10.5 \mathrm{~km}$, $21 \mathrm{~d}$ ) as the first variable to split turtles into 2 initial 'heavily oiled' and 'not heavily oiled' nodes, and final, pruned classification trees always included this variable. Therefore, a final CART model included only 2 response classes - heavily oiled, or exposed but not heavily oiled - and the number of daily oil footprint intersections in the $10.5-\mathrm{km}, 21-\mathrm{d}$ scenario as the only splitting variable. Results of this CART model demonstrated that this sole variable classified all 61 heavily oiled turtles successfully.

In our final step, we estimated the probability of heavy oiling of each turtle that was captured or sighted during boat-based rescue operations ( $\mathrm{n}=939$ turtles) and aerial surveys $(\mathrm{n}=792$ turtles at 644 locations). We used a binomial logistic regression with the number of daily oil footprint intersections in the $10.5-\mathrm{km}, 21-\mathrm{d}$ scenario as the only independent variable. We then used this model to estimate the proba- 

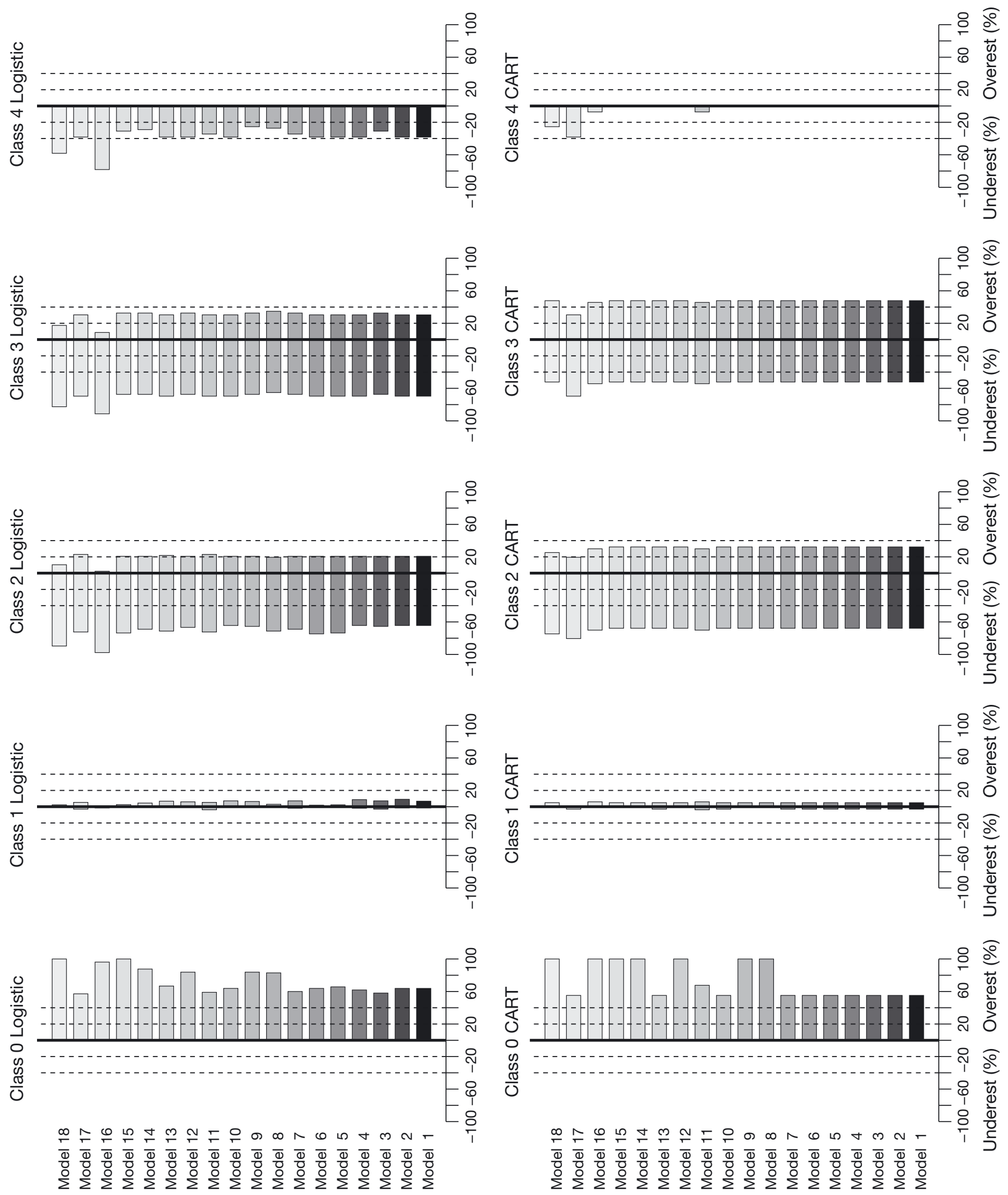
bility of heavy oiling for all turtles observed within the DWH spill area and period. Sample sizes for individual species, as well as the numbers of turtles not identified to species, prevented estimation of heavy oiling probability for each species separately; thus, estimates were generated for sea turtles generally.

\section{Phase 4: Estimating daily probabilities of heavy oil exposure across the DWH footprint}

In addition to heavy oiling probabilities for all turtle location data, we also used the above approach to generate spatial surfaces of daily heavy oiling exposure probabilities across the entire DWH oil footprint. This adaptation of our oiling probability model provided a generalized spatio-temporal description of probabilities of heavy oil exposure at the sea surface. The purpose of this step was to provide the areal extent within which surface-pelagic turtle density estimates (McDonald et al. 2017) were applied to calculate total turtle abundance and oil exposure (DWH Trustees 2016b). Because densities of surface-pelagic turtles were estimated based on directly observed degrees of oiling determined by veterinary evaluation (Stacy 2012, McDonald et al. 2017), our modeling approach was not required to estimate probabilities of heavy oiling for these turtles. Instead, our modeling approach was adapted to delineate the area within which turtles were likely to have encountered some degree of heavy oil exposure; in separate, subsequent analyses, this area was combined with density estimates reported to quantify total abundance, exposures, and ultimately mortality of surface-pelagic turtles (DWH Trustees 2016b, McDonald et al. 2017).

Whereas turtle capture/sighting locations and dates were used as the input points in Phase 3, we used centroid points of a 5-km grid in Phase 4; eligible centroids were those at any date within $10.5 \mathrm{~km}$ of any daily oil footprint that did not intersect land. Specifically, we calculated the number of intersections between spatially buffered centroid points and the daily surface oil footprints between April 23 and August 11,
2010. For quantification of intersections between surface oil and centroids, we used the same spatial and temporal buffering procedure as for the turtle observation data, but used only the broadest-scale scenario (i.e. 10.5-km buffer, 21-d window). This approach produced daily probabilities of heavy oiling across the entire cumulative oil footprint, as described by the relationship between the observed degree of turtle oiling and the oil environment before a turtle's capture.

\section{Assumptions in our modeling approach}

We note important assumptions about our approach that influenced our calculation of the probability of turtles being heavily oiled. First, the surface oil data used in the model did not include any information about the relative thickness of oil in time and space. Therefore, the correlation between the proximity of surface oil and the degree of oiling observed on turtles was based solely on the presence of oil of any thickness on the sea surface in a given place and time. Second, our approach quantified the number, not the extent or degree, of intersections between turtle location and surface oil. Third, we fit the model to the relationship between observed surface oil and observed degree of oiling of small, surface-pelagic juveniles; when estimating probabilities of heavy oiling for larger, neritic turtles, the model assumed that the processes that governed heavy oil exposure were comparable for larger turtles. Specifically, although exposure risk probably varied non-uniformly with time at the surface, and surface-pelagic turtles spend significantly more time at the surface $(\geq 90 \%$; Bolten 2003, Mansfield et al. 2014) than do neritic turtles ( $\leq 10 \%$; Bolten 2003, Southwood Williard 2013, Hochscheid 2014), we assumed that the observed and modeled relationships between surface oil and degree of oiling derived for surface-pelagic turtles could be translated to estimation of degree of oil exposure for neritic turtles. This assumes that the spatio-temporal proximity of surface oil to turtle locations alone indicates the potential degree of oil expo-

Fig. 5. Misclassification rates of estimated degree of oiling using ordinal, multinomial logistic regression models (top row) and CART models (bottom row). Models incorporated different combinations of explanatory variables to estimate oiling categories for turtles whose actual oiling categories were known (18 different variable combinations shown in this example). Candidate variables included distance from the wellhead, elapsed days (i.e. number of days between the beginning of the spill and the capture date), cumulative oil-days at the turtle capture location, and 1 to 2 different daily oil footprint intersection scenarios (i.e. the 4 scenarios shown in Table 1, as well as different combinations of the distance and time parameters of these scenarios). Each vertically paired set of classification results are for a specific oiling category (see Fig. 4). The $x$-axes indicate the percent of turtles whose estimated oiling category was above (overest) or below (underest) their actual oiling category (where $0=$ correct classification); the smaller the deviation from 0 , the better the classification rates of particular oiling categories by particular models. See 'Methods: Phase 3' for more details 
sure, and does not incorporate information about how long turtles must be exposed to oil while at the surface to become oiled to some degree. However, these differences in surface time for the 2 life stages were incorporated into estimates of mortality relative to degree of oil exposure (DWH Trustees 2016b).

We concluded that these assumptions were reasonable because all turtles, regardless of size, must spend significant time at the surface and would have been exposed in areas where oil was consistently present. Furthermore, the number of intersections between daily surface oil footprints, turtle locations, and the turtles' observed degree of oiling, showed a positive relationship (Fig. 4); this indicated that the presence of surface oil was likely positively correlated with other factors, such as oil thickness, which may have influenced the degree of turtle oiling.

\section{MODEL RESULTS AND IMPLICATIONS}

\section{Probabilities of heavy oiling for sea turtles}

The binomial logistic regression using the broadestscale daily oil footprint intersection scenario as the only independent variable produced probabilities of heavy oiling for all sea turtles within the DWH spill footprint. Specifically, this model described the relationship between the number of daily oil footprint intersections and the probability of heavy oiling as what resembled a sigmoid function (Fig. 6). The model estimated a low probability of heavy oiling $(<0.01)$ when the number of daily oil footprint intersections was lower than 7 in the previous $21 \mathrm{~d}$, and it estimated an increased probability of heavy oiling (up to $51.1 \%$ ) when the number of daily oil footprint intersections in the previous $21 \mathrm{~d}$ was 9 or higher (Fig. 6).

Oceanic versus neritic turtles. We compared the number of daily oil footprint intersections and the probabilities of heavy oiling for surface-pelagic turtles (Fig. 7A,C) with those estimated for neritic turtles (Fig. 7B,D). Distributions of daily oil footprint intersections and heavy oiling probabilities were rightskewed for both survey datasets: only $22 \%$ of turtles observed during boat-based surveys and $12 \%$ of turtles observed during aerial surveys had 9 or more intersections; these were the minimum number of intersections over the previous $21 \mathrm{~d}$ associated with turtles directly assessed as heavily oiled (Fig. 4D). Proportionally fewer turtles sighted during aerial surveys had high probabilities of heavy oiling compared to turtles documented during rescue operations. This was probably because the aerial surveys were con-

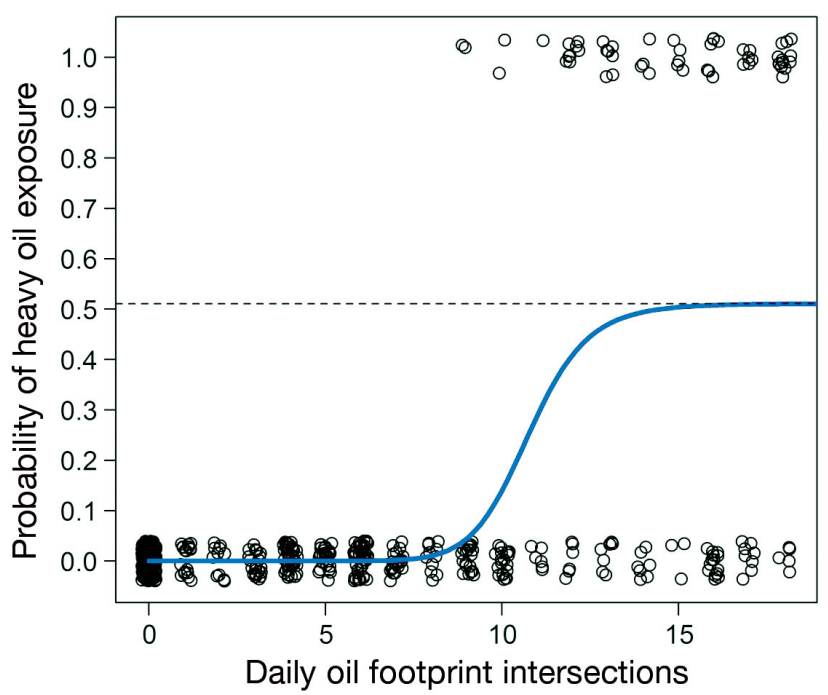

Fig. 6. Results of binomial logistic regression using the number of daily oil footprint intersections in the previous $21 \mathrm{~d}$ with spatially buffered $(10.5 \mathrm{~km})$ turtle locations as the sole independent variable. The model estimated the probability of heavy oiling for turtles with known oiling status (i.e. those captured and directly evaluated during rescue efforts). Actual oiling classes of turtles (see Fig. 4 for definitions) are split into Class 4 (probability $=1.0$ ) or Classes $0-3$ (probability $=0.0$ ), and data-points are jittered to show full dataset. The maximum probability of heavy oiling was 0.51 . Blue line: model estimates of probability of heavy oiling as a function of the number of daily oil footprint intersections in the previous $21 \mathrm{~d}$ within $10.5 \mathrm{~km}$

ducted on the continental shelf; many of them were more than $100 \mathrm{~km}$ from the wellhead, in places that were not as affected by surface oil as areas searched by boat (DWH Trustees 2016b). However, it is also possible that heavily oiled neritic turtles were more difficult for plane-based observers to see, particularly if dark-colored, oiled turtles surfaced in or near a dark-colored oil slick. Indeed, McDonald et al. (2017) calculated different sightability functions for turtles captured during rescue operations based on oiling category, such that the distance at which observers could reliably see turtles declined with increasing oiling category. However, because the oiling status of neritic turtles was not recorded, we could not further explore the possibility that oiling status might have influenced observers' detection of turtles.

Probabilities over time. The numbers of daily oil footprint intersections over the previous $21 \mathrm{~d}$ and the heavy oiling probabilities showed similar temporal relationships, with the highest values for both variables between late May and early July, and then rapid declines from July into August and later in 2010 (Fig. 8). These trends reflected patterns of oil movement across the northern GoM. Surface oil footprints 


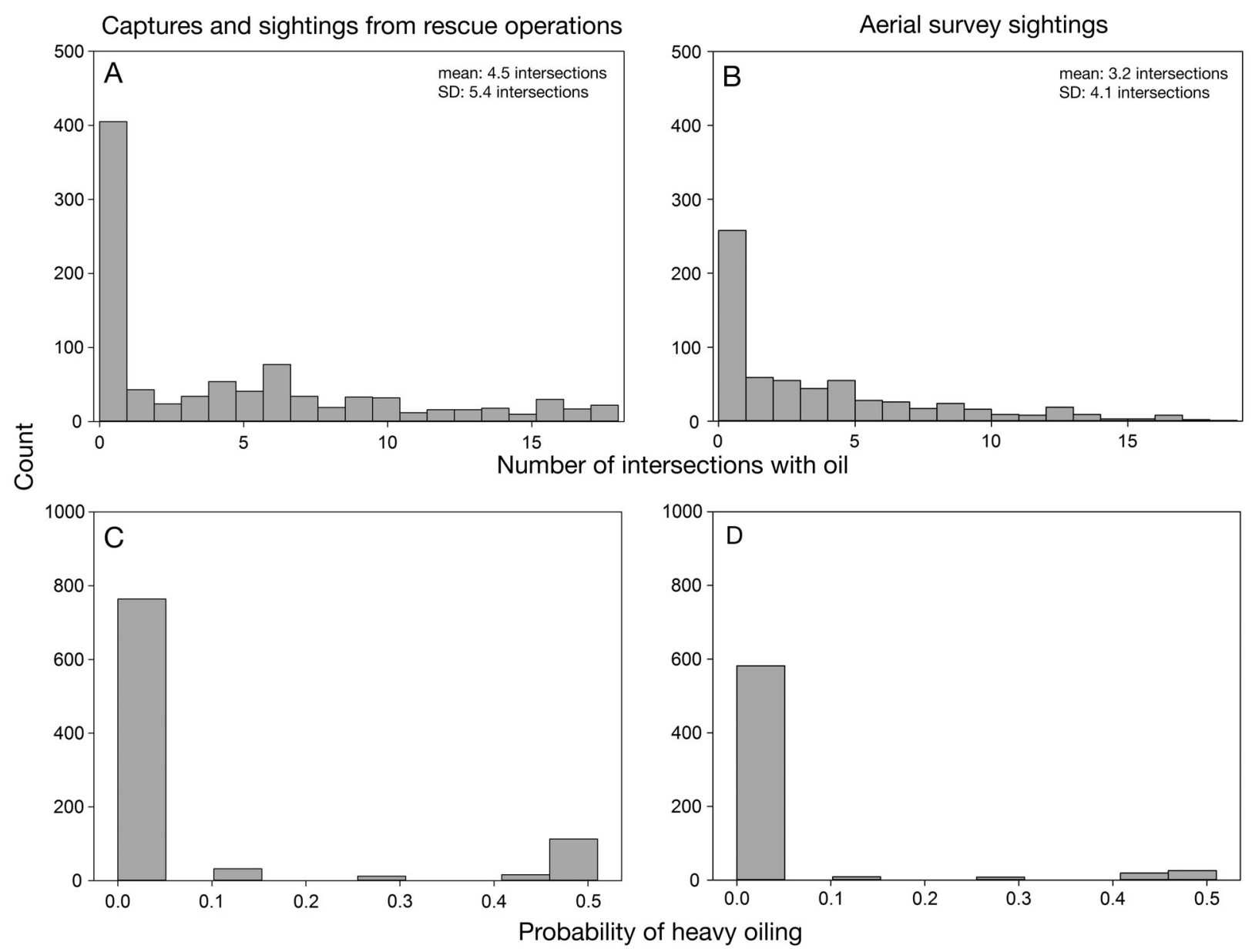

Fig. 7. (A,B) Number of intersections of daily oil footprints over the previous $21 \mathrm{~d}$ and $(\mathrm{C}, \mathrm{D})$ probabilities of heavy oiling for $(A, C)$ turtles documented during rescue operations (i.e. surface-pelagic turtles) and (B,D) aerial surveys (i.e. neritic turtles)

peaked in size in mid-June 2010, and began to dissipate in mid- to late July 2010 after the well was capped and oil finally ceased flowing into the ocean (DWH Trustees 2016d).

While there was no detectable surface oil in the northern GoM after August 11, 2010, there was still the possibility that a turtle observed in mid-August (for instance) had been exposed to detectable surface oil earlier. Instead of truncating our datasets at the last day of observable surface oil in the SAR data, we analyzed the complete set of captures and sightings data for the entire study period (into September 2010), because some turtles still could have had nonzero probabilities of heavy oiling within the temporal window of 21 days prior to capture or sighting. Consistent with the SAR-based surface oil observations, no heavily oiled turtles were rescued from the northern GoM after August 1, and the vast majority of turtles rescued after August 11 were unoiled or in the lowest oiling categories (Fig. 1). Therefore, we concluded that despite the lack of observable surface oil after August 11, our model's approach to estimating probabilities of heavy oiling still accurately characterized the relative potential for heavy oil exposure throughout the entire period when turtles may have been exposed to oil.

Probabilities across the DWH oil footprint. To illustrate how the potential exposure to heavy oiling changed in space and time at the scale of the entire DWH footprint, we generated daily maps of heavy oiling probabilities using the same binomial logistic regression approach that we used for estimating oiling categories for turtles (Fig. 9A; Video S1 in the Supplement at www.int-res.com/articles/suppl/n033 p051_supp/). We then overlaid locations and heavy oiling probabilities for all turtles captured or sighted during rescue operations (Fig. 9B) and aerial surveys (Fig. 9C) on the average probability of exposure to heavy oil estimated across the DWH oil footprint (see Video S1 in the Supplement for daily probabilities of heavy oiling for all turtles observed across the cumulative oil footprint). 

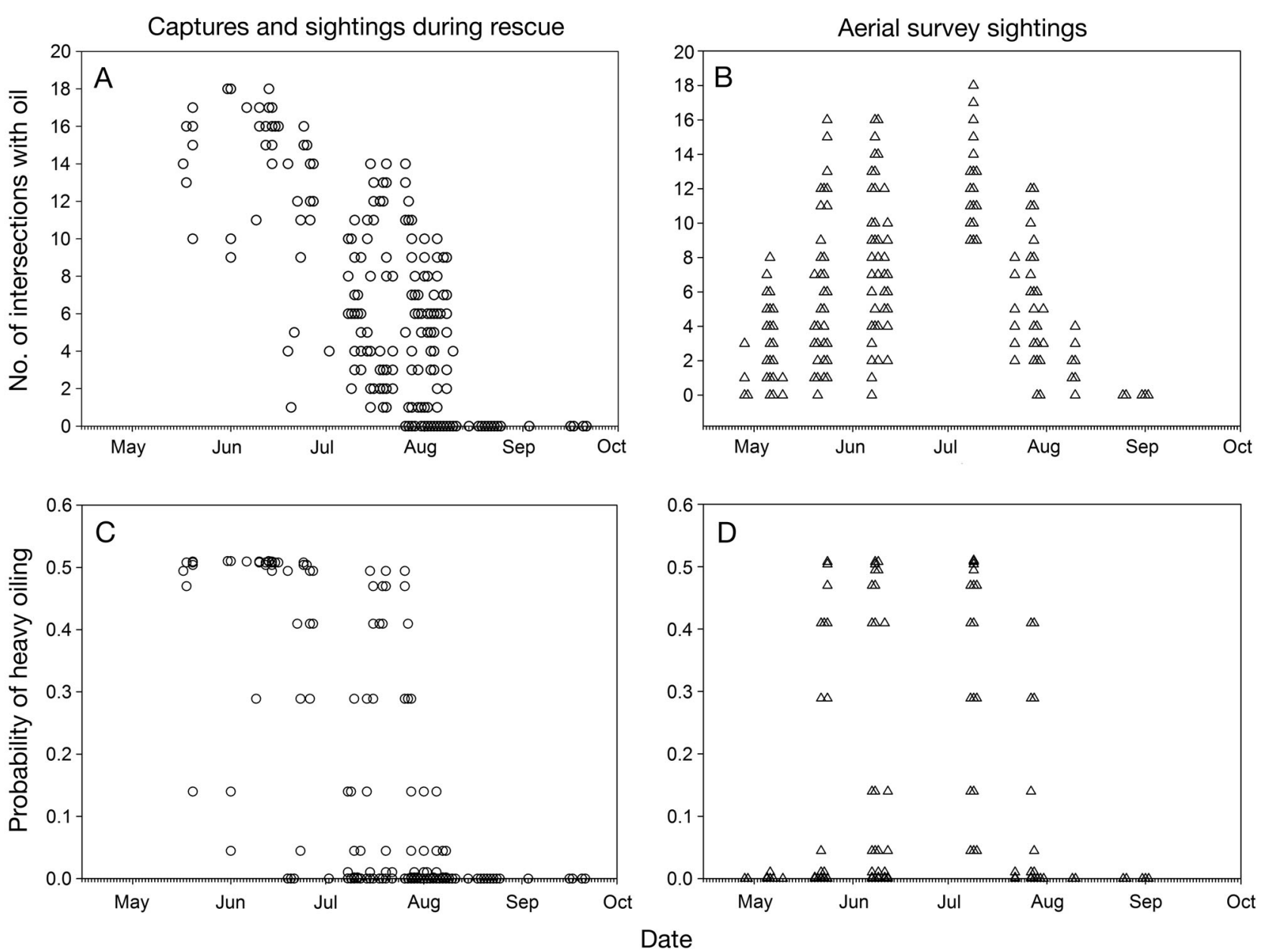

Fig. 8. (A,B) Number of intersections of daily oil footprints over the previous $21 \mathrm{~d}$ and $(\mathrm{C}, \mathrm{D})$ probabilities of heavy oiling for $(A, C)$ turtles documented during rescue operations (i.e. surface-pelagic turtles) and $(B, D)$ aerial surveys (i.e. neritic turtles), by date. Each symbol represents a single turtle

The highest probabilities of heavy oil exposure were limited to areas nearest the wellhead, and the probability of heavy oiling decreased with increasing distance from the wellhead (Fig. 9; Video S1 in the Supplement). Although aerial surveys were restricted to water depths of $<200 \mathrm{~m}$, and the survey area boundaries were farther westward than areas where rescue operations occurred (DWH Trustees 2016b), the estimated distribution of heavily oiled neritic tur- tles was similar to the estimated distribution of heavily oiled oceanic turtles (Fig. 9). Given this broad agreement between empirical patterns of degree of oiling of turtles and surface oil in space and time across the DWH footprint, our modeling approach produced reasonable estimates of heavy oiling probability for turtles - and surface habitats - that were not directly observed during NRDA response and survey efforts.

Fig. 9. (A) Average daily heavy oiling probabilities for the centroids of all $5 \times 5 \mathrm{~km}$ grid cells that intersected the Deepwater Horizon (DWH) oil footprint. Area delineated by non-zero probabilities of heavy oil exposure (i.e. cells not colored grey) provided the spatial extent to which surface-pelagic turtle densities were applied to quantify total abundance, exposures, and injuries to this life stage (DWH Trustees 2016b, McDonald et al. 2017). (B,C) Oiling probabilities estimated for (B) surface-pelagic juvenile turtles rescued or sighted during boat-based operations (pentagons) and (C) neritic turtles observed during aerial surveys (triangles); these layers are overlaid on the DWH daily footprint (lightened to enhance visualization). Color key applies to all panels, and shows transition from non-zero probabilities of heavy oiling to the highest probabilities of heavy oiling shown in Fig. 6 (see 'Methods: Phase 4' for description of oiling probability estimation). No values $\geq 0.40$ appear in (A) because these are average probabilities for each location across the entire spill period (i.e. all values from minima to maxima are included); daily oiling probabilities exceeded 0.40 in several locations across the spill footprint (see also Video S1 in the Supplement) 


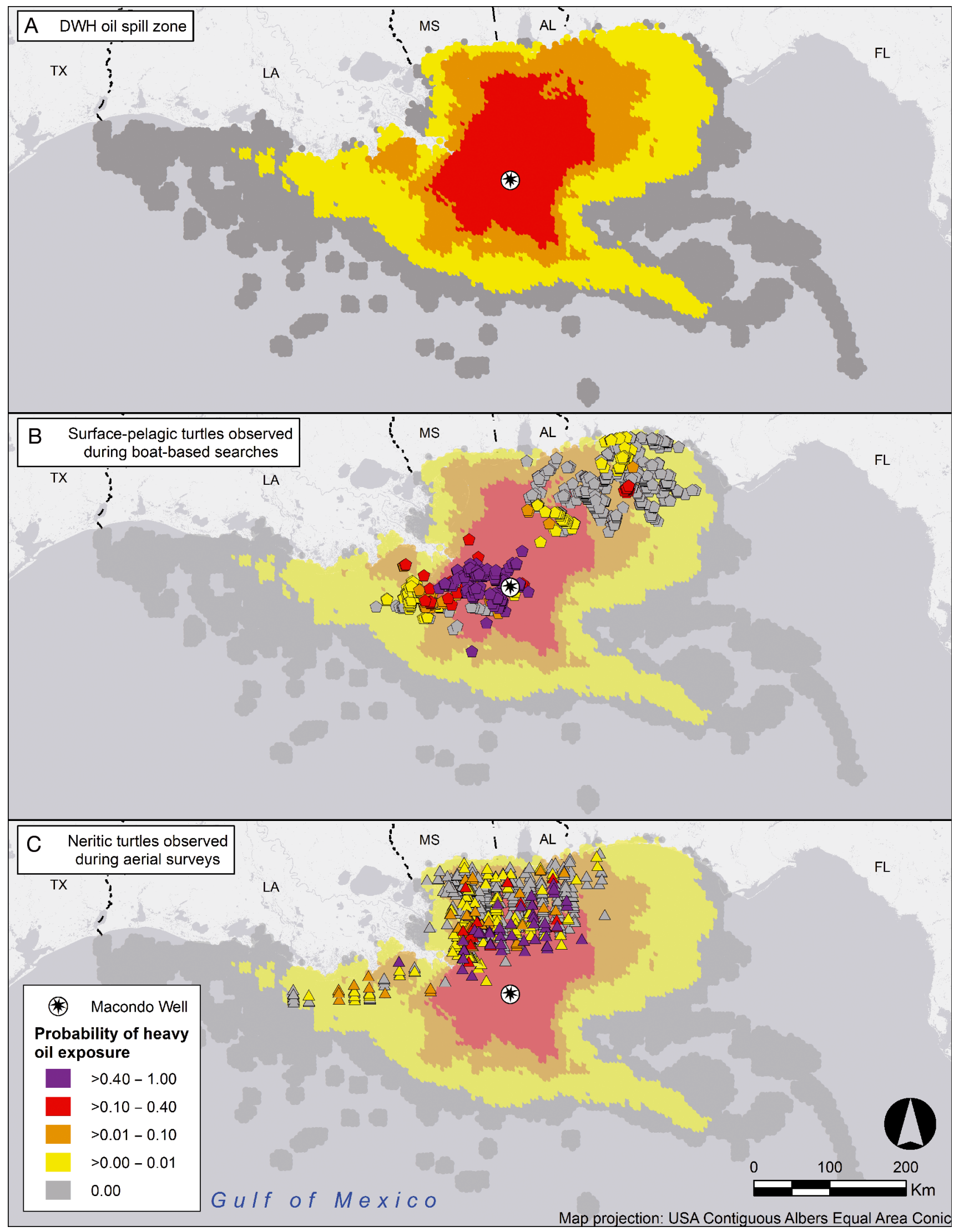




\section{Conclusions and implications for future wildlife injury assessments in marine oil spills}

In marine oil spills, systematic documentation of the presence and distribution of wildlife relative to oil - as well as wildlife health status, exposures to oil, and adverse effects of those exposures - can be extremely challenging (Piatt \& Ford 1996, Peterson et al. 2003, Shigenaka 2003). The probability model approach that we developed for assessing injuries to sea turtles in the wake of the DWH spill provided a measure of the probability that a turtle in the northern GOM would have encountered heavy surface oil. Our approach was a simple yet informative proxy for the relative probability of oil exposure for turtles in a certain area at a certain time. Furthermore, our analysis bridged the gap between estimated turtle abundance and estimated mortality because it quantified the degree of oil exposure for all turtles across the entire DWH oil spill footprint and period (DWH Trustees 2016b), where direct observation of all turtle exposures to oil was impossible. This allowed expansion of the injury quantification from sea turtles and oil exposures that were directly observed in the field to a more holistic quantification of the full extent and magnitude of potential sea turtle injuries caused by the DWH oil spill (DWH Trustees 2016b, McDonald et al. 2017).

Beyond the current example of sea turtle injuries caused by the DWH oil spill, our approach had several important advantages for estimating exposures of wildlife-including, but not limited to, sea turtles - to surface oil. First, it combined ubiquitous, reliable data (satellite-derived measurements of surface oil and empirical observations of the extent of oiling on animals) to statistically estimate the probability of heavy oil exposure in cases where the former data type was available, but not the latter. Second, our approach can be adapted to various situations in which the scale of the potential oil exposures exceeds the scale of the available documentation of oil exposures.

Assessment of oil exposures and their effects on marine wildlife requires thoughtful approaches for collecting direct observational data in the field and for expanding on these observations to produce estimates of impacts at scales that match the full nature and magnitude of the spill. The oiling probability modeling tool that we have described here was one such approach. Our approach used field-collected information about the degree of oil exposure to construct a modeling framework that described general relationships among turtles, the degree of oiling, and surface oil. Similar approaches could be useful for estimating exposures of natural resources in future marine oil spills, particularly in spills that primarily affect offshore areas distant from land.

Acknowledgements. This work was part of the DWH NRDA being conducted cooperatively among NOAA, other federal and state Trustees, and BP PLC. The findings and conclusions in this paper are those of the authors and do not necessarily represent the view of NOAA or of any other natural resource Trustee for the BP/Deepwater Horizon NRDA. We thank the many colleagues who spent innumerable hours in challenging conditions during DWH response efforts to rescue and rehabilitate sea turtles, as well as colleagues who contributed to the NRDA process that informed the analyses presented here. We thank A. Andre, B. Blum, T. Brosnan, D. Callow, K. Hart, J. Lipton, D. Lane, E. Miles, C. Quinn, S. Renfrow, A. Solow, R. Takeshita, D. Wehner, and B. Witherington for comments, edits, and guidance that improved this manuscript.

\section{LITERATURE CITED}

Bolten AB (2003) Variation in sea turtle life history patterns: neritic vs. oceanic life history stages. In: Lutz PL, Musick JA, Wyneken J (eds) The biology of sea turtles, Vol 2. CRC Press, Boca Raton, FL, p 243-258

Camacho M, Calabuig P, Luzardo OP, Boada LD, Zumbado M, Orós J (2013) Crude oil as a stranding cause among loggerhead sea turtles (Caretta caretta) in the Canary Islands, Spain (1998-2011). J Wildl Dis 49:637-640 PubMed 3

DWH (Deepwater Horizon Natural Resource Damage Assessment) Trustees (2016a) Deepwater Horizon oil spill programmatic damage assessment and restoration plan and programmatic environmental impact statement, Chapter 4. www.gulfspillrestoration.noaa.gov/wp-content/ uploads/Chapter-4_Injury_to_Natural_Resources_508.pdf (accessed 16 Feb 2016)

DWH (Deepwater Horizon Natural Resource Damage Assessment) Trustees (2016b) Deepwater Horizon oil spill programmatic damage assessment and restoration plan and programmatic environmental impact statement, Chapter 4, Section 4.8. www.gulfspillrestoration.noaa.gov/wpcontent/uploads/Chapter-4_Injury_to_Natural_Resources_ 508.pdf (accessed 16 Feb 2016)

DWH (Deepwater Horizon Natural Resource Damage Assessment) Trustees (2016c) Deepwater Horizon oil spill programmatic damage assessment and restoration plan and programmatic environmental impact statement, Chapter 2. www.gulfspillrestoration.noaa.gov/wp-content/ uploads/Chapter-2_Incident-Overview_508.pdf (accessed 16 Feb 2016)

DWH (Deepwater Horizon Natural Resource Damage Assessment) Trustees (2016d) Deepwater Horizon oil spill programmatic damage assessment and restoration plan and programmatic environmental impact statement, Chapter 4, Section 4.2. www.gulfspillrestoration.noaa. gov/wp-content/uploads/Chapter-4_Injury_to_Natural_ Resources_508.pdf (accessed 16 Feb 2016)

ERMA (2015) Web application: Deepwater Gulf Response. Environmental Response Management Application, Na- 
tional Oceanic and Atmospheric Administration, Seattle, WA. http://gomex.erma.noaa.gov/erma.html (accessed 16 Nov 2015)

* Garcia-Pineda O, Zimmer B, Howard M, Pichel W, Li X, MacDonald I (2009) Using SAR images to delineate ocean slicks with a texture-classifying neural network algorithm (TCNNA). Can J Rem Sens 35:411-421

Garrison L (2015) Estimated lethal and sub-lethal injuries of sea turtles on the continental shelf in the Northern Gulf of Mexico based on aerial survey abundance estimates and surface oiling. DWH Sea Turtles Technical Working Group Report. https://pub-dwhdatadiver.orr.noaa.gov/ dwh-ar-documents/894/DWH-AR0149505.pdf

Graettinger G, Holmes J, Garcia-Pineda O, Hess M and others (2015) Integrating data from multiple satellite sensors to estimate daily oiling in the Northern Gulf of Mexico during the Deepwater Horizon Oil Spill. NOAA Tech Rep. US Department of Commerce, Seattle, WA. https:// pub-dwhdatadiver.orr.noaa.gov/dwh-ar-documents/925/ DWH-AR0071402.pdf

Hart KM, Lamont MM, Sartain AR, Fujisaki I (2014) Migration, foraging, and residency patterns for northern Gulf loggerheads: implications of local threats and international movements. PLoS ONE 9:e103453

'Hochscheid S (2014) Why we mind sea turtles' underwater business: a review on the study of diving behavior. J Exp Mar Biol Ecol 450:118-136

Lamont MM, Putman N, Fujisaki I, Hart K (2015) Spatial requirements of different life-stages of the loggerhead turtle (Caretta caretta) from a distinct population segment in the northern Gulf of Mexico. Herpetol Conserv Biol 10:26-43. http://www.herpconbio.org/Volume_10/ Issue_1/Lamont_etal_2015.pdf

Leifer I, Lehr WJ, Simecek-Beatty D, Bradley E and others (2012) State of the art satellite and airborne marine oil spill remote sensing: application to the BP Deepwater Horizon oil spill. Remote Sens Environ 124:185-209

Lemon SC, Roy J, Clark MA, Friedman PD, Rakowski W (2003) Classification and regression tree analysis in public health: methodological review and comparison with logistic regression. Ann Behav Med 26:172-181

'Mansfield KL, Wyneken J, Porter WP, Luo J (2014) Satellite tracks of neonate sea turtles redefine the 'lost years' oceanic niche. Proc R Soc B 281:20133039

Editorial responsibility: Brendan Godley, University of Exeter, Cornwall Campus, UK
McDonald TL, Schroeder BA, Stacy BA, Wallace BP and others (2017) Density and exposure of surface-pelagic juvenile sea turtles to Deepwater Horizon oil. Endang Species Res 33:69-82

Mitchelmore CL, Bishop C, Collier T (2017) Toxicological estimation of mortality of oceanic sea turtles oiled during the Deepwater Horizon oil spill. Endang Species Res 33: 39-50

* Peterson CH, Rice SD, Short JW, Esler D, Bodkin JL, Ballachey BE, Irons DB (2003) Long-term ecosystem response to the Exxon Valdez oil spill. Science 302:2082-2086

Piatt JF, Ford RG (1996) How many seabirds were killed by the Exxon Valdez oil spill? In: Rice SD, Spies RB, Wolfe DA, Wright BA (eds) Proc Exxon Valdez Oil Spill Symp, 2-5 February 1993, Anchorage, AK. American Fisheries Society, Bethesda, MD, p 712-719

*Putman NF, Mansfield KL (2015) Direct evidence of swimming demonstrates active dispersal in the sea turtle 'lost years'. Curr Biol 25:1221-1227

'Shaver DJ, Hart KM, Fujisaki I, Rubio C and others (2013) Foraging area fidelity for Kemp's ridleys in the Gulf of Mexico. Ecol Evol 3:2002-2012

Shigenaka G (2003) Oils and sea turtle: biology, planning, and response. Office of Response and Restoration, NOAA Ocean Service, Seattle, WA

Southwood Williard A (2013) Physiology as integrated systems. In: Musick JA, Wyneken J, Lohmann KJ (eds) Biology of sea turtles, Vol 3. CRC Press, Boca Raton, FL, p 1-30

Stacy B (2012) Summary of findings for sea turtles documented by directed captures, stranding response, and incidental captures under response operations during the BP DWH MC252 oil spill. DWH Sea Turtles Technical Working Group Report. https://pub-dwhdatadiver.orr. noaa.gov/dwh-ar-documents/894/DWH-AR0149670.pdf

Wallace BP, DiMatteo AD, Hurley BJ, Finkbeiner EM and others (2010) Regional Management Units for marine turtles: a novel framework for prioritizing conservation and research across multiple scales. PLoS ONE 5: e15465

W Witherington B, Hirama S, Hardy R (2012) Young sea turtles of the pelagic Sargassum-dominated drift community: habitat use, population density, and threats. Mar Ecol Prog Ser 463:1-22

Submitted: December 10, 2015; Accepted: March 11, 2016 Proofs received from author(s): May 13, 2016 